\title{
Las voces del secreto: pasiones lesbianas en Silvina Ocampo, Julio Cortázar y Sylvia Molloy
}

\author{
Laura A. Arnés ${ }^{1}$
}

\begin{abstract}
SÍNTESIS
A partir del ejercicio de una lectura desviada sobre una selección de textos de Silvina Ocampo, Julio Cortázar y Sylvia Molloy, este artículo busca pensar el término voz lesbiana, en tanto concepto pero también como instrumento de lectura. Partiendo de la idea de que la construcción de la voz lesbiana plantea problemas literarios y políticos, se profundizará en los modos especificos que adopta, sobre todo en la relación que mantiene con el pasado y con el secreto y en las definiciones que construye en relación con el cuerpo lesbiano. Mientras que en los cuentos de Ocampo y Cortázar el análisis se centrará, mayormente, en la relación que proponen entre voz lesbiana, imposibilidad, pasión y duelo, en la novela de Sylvia Molloy se ocupará, sobre todo, de la relación entre voz lesbiana y secreto, para sugerir, por último, que sobre el final de la novela se abren nuevas posibilidades para la construcción de esa voz.
\end{abstract}

\begin{abstract}
By practicing a queer reading on a selection of texts by Silvina Ocampo, Julio Cortázar and Sylvia Molloy, this article seeks to think the term lesbian voice, as a concept but also as a reading tool. Based on the idea that the construction of the lesbian voice raises literary and political problems, the analysis will focus on the specific manners it adopts, especially on the relation it holds with the past and the secret and on the definitions that it builds in relation to the lesbian body. Whereas in the stories of Ocampo and Cortá$z$ ar the analysis will centre, mainly, on the relation that the texts propose between lesbian voice, impossibility, passion and grief, in Sylvia Molloy's novel it will deal, especially, with the relationship between lesbian voice and secret, to suggest, at last, that towards the end of the novel new possibilities, related to the construction of this voice, seem to open.
\end{abstract}

Palabras clave: Literatura argentina, voz lesbiana, secreto, cuerpo.

Keywords: Argentinian literature, lesbian voice, secret, body. 
“El silencio absoluto resulta enseguida siniestro, es como la muerte, mientras que la voz es el primer signo de vida... esa división, que se establece entre la voz y el silencio, es quizás más elusiva de lo que parece: no todas las voces se oyen,

y quizás las más intrusivas y apremiantes sean las voces no oídas"

Mladen Dólar

Lacan sostuvo a los conceptos "voz" y "silencio" en una relación semejante a la de figura y fondo pero con una diferencia: la voz se articularía sobre el silencio actualizándolo, haciéndolo presente como figura de una ausencia (Costantini, 2009). Por otro lado, explicó que en la voz se deslizaría el deseo del Otro al tiempo que ésta se vería obligada, invariablemente, a resonar en su vacío. Rescato, entonces, esa dimensión de la voz en la que se opone a su propia transparencia, la que permite (frente al logos) la intrusión de la otredad y del goce ${ }^{2}$.

Considerando que la voz está tan presente en lo que se oye como en lo que se lee porque no está ligada esencial ni necesariamente a la sustancia sonora, y provocando una torsión en la idea de Dólar $(2007,26)$-presentada como epígrafe de esta introducción-, sostendré que una de estas voces intrusivas (en la literatura hegemónica argentina, frente al pudor de la crítica literaria) y agónicamente apremiantes (en su necesidad de ser leídas y escuchadas) es la voz lesbiana.

Como se notará, la palabra lesbiana no funciona acá como sustantivo sino como modificador o, más específicamente, como catacresis: metáfora que consiste en emplear una palabra, más allá de su sentido estricto, para designar una cosa que carece de nombre especial. Como explica Amy Villarejo, "Reading lesbian as a catachresis allows to examine the slippery movement that lesbian appearance reveals and conceals between sexual difference and social relations" $(2003,26)$.

La voz lesbiana será definida, provisoriamente, no sólo como la construcción literaria de una primera persona femenina que narra su pasión amorosa por otra mujer sino como ese espacio donde una sexualidad femenina diferencial, al presentarse como un problema para la instancia narrativa -punto y materia de la 
enunciación-, pone en escena el problema del deseo lesbiano como problema de representación (o de representabilidad).

El término voz lesbiana funcionará, entonces, como un concepto y como un instrumento de lectura que permitirá profundizar en el análisis de una retórica sexual que sostiene, a la vez, ciertas construcciones retóricas de los géneros y, por eso mismo, de la(s) lesbiana(s). Porque, innegablemente, todos los personajes literarios son elaborados tanto a partir de códigos específicos de la ficción como a partir de valores sobre la sexualidad, vigentes en el contexto cultural de producción.

Puede entenderse, además, que la voz lesbiana definirá al cuerpo lesbiano y a sus usos, y los modos en que lo haga no sólo implicará un modo determinado de construcción de esa voz, sino que planteará problemas literarios y políticos, poniendo en evidencia tanto políticas de la literatura, como de la lengua, culturales y del género sexual.

Pero la voz lesbiana tiene, además, una peculiaridad: se construye sobre la memoria. Y esto cobra mayor importancia si se tiene en cuenta que, en las narrativas culturales (especialmente en la narrativa heterosexual), los paradigmas secuenciales y sus lógicas resultan fundamentales para la organización y jerarquización de las identidades sexuales. Como desarrolla Annamarie Jagose (2002), estructura narratológica y disciplinaria se presentan en una estrecha relación.

En relación con esto, si consideramos que, como propone Judith Butler, el tabú contra el incesto es, de manera implícita, un imperativo contra la homosexualidad (lo que implicaría una inclinación libidinal originalmente homosexual y generaría el fenómeno desplazado del deseo heterosexual), queda claro cómo la alteración (narrativa) del orden del deseo genera una coherencia jerárquica en el nivel temporal que desplaza (hasta hacer caer del tablero, es decir, hasta volver irrecuperable e incluso invisible) al deseo homosexual ${ }^{3}$.

No sorprende, entonces, que así como Jagose (2002) nota que sucede en las conclusiones de Freud ${ }^{4}$, también en los textos analizados el deseo lesbiano se presentará como un problema mnémico. El presente narrativo es un después que narra un antes: un pasado que se actualiza a condición de ser leído más allá del registro de la palabra.

Acorde con esto, la pasión lesbiana se estructurará, en los 
textos analizados, como pasado recordado o, a veces, como lo reprimido que irrumpe y se filtra entre los pliegues y las fisuras de las palabras de las protagonistas. Sin embargo, si bien es en ese retorno a un estado previo que el personaje lesbiano y su voz van a construirse (en el presente), lo harán, generalmente, sin posibilidades de continuidad (en el futuro). Es por esto que la voz lesbiana, en su carácter retrospectivo (aunque no sólo por él), se fundará sobre el registro de una pasión y el de una pérdida.

A la lógica temporal del deseo lesbiano se contrapondrá el presente jerárquico de la heterosexualidad e incluso de la homosexualidad masculina (como se verá en el tercer apartado). Pero el recuerdo, en todas sus variantes -la confesión, la declaración e incluso el olvido-, en tanto construcción de una voz y de un pasado, tiene tres problemas principales: no es completo, es siempre vulnerable a la interrupción y depende de la escucha (o de la lectura).

Y por último, la voz lesbiana tiene otra característica central para este análisis: nunca se enuncia como lesbiana. Es decir que, de algún modo, emerge como negación. Como ya ha explicado Eve Kosovsky Sedwick (2002), el deseo homo-erótico, como consecuencia de la discriminación de una cultura hetero-normativa, se ha estructurado, históricamente, entre lo secreto, lo sabido y lo no dicho. Y los textos seleccionados no se presentarán como excepción.

A partir de esto, me interesará pensar, en primer lugar, la construcción de lo que llamaré secreto a voces o, mejor dicho, voces del secreto, en tanto estrategia de representación e, incluso, de visualización. En segundo lugar, intentaré analizar los modos en que este conflicto se duplica y resignifica en la construcción de los cuerpos y rostros de las protagonistas.

No es novedad que lesbianismo y campo de visión se han mantenido, históricamente, en una relación conflictiva. Pero, si coincidimos con Jagose $(2002,2)$ en que la figura familiar de la invisibilidad lesbiana está sostenida por una paradoja estructurante (sería la condición de entrada de la lesbiana al campo cultural), leer esta invisibilidad -ese secreto- en términos de estrategia de representación resultará productivo no sólo para pensar lo lesbiano sino los diferentes sentidos que promueve -es decir, sus potencialidades-, así como los posibles diálogos que establece con otros textos. 
Propongo, a partir de lo establecido, una lectura de los cuentos "La barca" (1976) de Julio Cortázar, "Carta perdida en un cajón" (1959), “El Lazo" (1961), “Memorias secretas de una muñeca" (1987) y "El piano incendiado" (1988) de Silvina Ocampo, y de la novela El común olvido (2002) de Sylvia Molloy, que preste especial atención a las distintas estrategias de escritura a través de la cuales la voz lesbiana, delineando figuras de lo infigurable, cobra cuerpo (y lo construye); a los modos en que esta voz irrumpe en la literatura argentina (a mediados del siglo XX) y se transforma con el correr de los años, poniendo siempre en tensión el binomio sexualidad-textualidad y dando voz a una herida amorosa y social que será construida en la misma superficie textual.

2

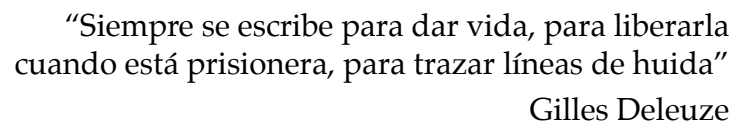

Silvina Ocampo y Julio Cortázar ya han sido reunidos por la crítica literaria en tanto autores de lo que se llamó cuento fantástico ${ }^{5}$. Sin embargo, alejándome de este tipo de lecturas, voy a analizar a estos dos autores desde otra perspectiva, para proponer algunos de sus textos como espacio de emergencia de una voz lesbiana dentro de este género narrativo 6 .

"La barca" es un cuento escrito por Julio Cortázar en 1954, y reescrito en 1976, que relata un viaje a Venecia realizado por dos amigas, Valentina y Dora, en el que la primera establece una relación amorosa con Adriano, otro turista que habían conocido, con anterioridad, en Roma. Lo que resulta interesante es que, en su segunda versión, "La barca" no sólo viene precedido por un prólogo del autor, sino que el originario relato en tercera persona es interrumpido por una voz en primera persona (Dora) que va a poner, según explica Cortázar en el prólogo: “[...] las cartas boca arriba $[\ldots]$ " porque "[...] que ese suceder sea un texto y ella un personaje de su escritura no cambia en nada su derecho igualmente textual a rebelarse frente a una crónica que juzga insuficiente o insidiosa" $(2000,136)$. 
Por su parte, los textos seleccionados de Ocampo (2007), publicados entre 1959 y 1988 están construidos, como la mayoría de sus cuentos, sobre la ambigüedad. "Carta perdida en un cajón", tal vez el más conocido de los cuatro, es, como su título lo indica, una carta escrita por una mujer a una ex compañera de escuela a quien ha vuelto a ver poco tiempo antes del momento de escritura. "El lazo" relata la violenta relación que mantuvo quien confiesa con otra compañera de trabajo a quien terminó asesinando. En "El piano incendiado", una mujer, reflexionando sobre una melodía que tiene en el recuerdo pero que desconoce, explica cómo, durante una fiesta, incendió el piano que su amiga tocaba al ver que miraba a un joven a los ojos. Por último, "Memorias secretas de una muñeca" relata, de manera más explícita que el resto, la relación amorosa que mantiene la protagonista con quien la salva durante una inundación, el engaño amoroso que sufre, su consecuente suicidio y, finalmente, la muerte también de las otras dos.

Será una cualidad (una potencialidad, tal vez) de la identidad de las protagonistas, constantemente insinuada por ellas mismas pero nunca dicha, lo que constituye el vacío significante de estos textos y el silencio que organiza centrífugamente los sentidos de esta lectura. $Y$ es que, como fue anticipado, y aunque en una primera instancia pueda parecer paradójico, una de las características principales de lo que llamo voz lesbiana es que nunca se enuncia como lesbiana, es decir, que emerge como negación.

Tomemos, a modo de ejemplo, el momento en que Dora, protagonista de "La barca", explica, refiriéndose a Valentina: "[...] sé que me pregunté si no sería como yo; esa manera de clavarme los ojos siempre un poco dilatados [...] casi en seguida supe que no" (Cortázar, 2000, 139). Y más tarde, agrega: "Pensar que ella les permitía [a los labios de Adriano] que conocieran cada rincón de su piel; hay cosas que me rebasan, claro que es cuestión de libido, we know we know we know" (2000, 145). El punto es que el pronombre inclusivo nos deja afuera. Como lectores(as) no sabemos.

O citemos el comienzo de la declaración de Bárbara, protagonista del cuento de Ocampo "Memorias secretas de una muñeca": "Soy independiente y libre de pensar y sentir como siento, sin la menor vergüenza" $(2007,247)$. Sentimientos que es la única 
capaz de poner en escena con una anécdota: “Entonces [Andrómana] me besó y puso su lengua en mi boca. Parecía una frutilla recién cortada. Dormirás conmigo en mi cama, ¿me comprendes? No te hagas la bebita ni cierres los ojos cuando te hablo" (2007, 249). La pregunta entonces es: los lectores, ¿comprendemos o cerramos los ojos cuando las protagonistas nos hablan? Porque, claramente, las normativas heterosexuales reconducen la percepción, generando recortes en las lecturas e históricos silencios.

En un contexto donde lo "pensable" y lo "decible" responden a un sistema y, por lo tanto, a un imaginario y a una narrativa heterosexual y sexista, las protagonistas lesbianas, en tanto sujetos sociales inmersos en una tradición (heterosexual) que no les corresponde, se encontrarán sin paradigma (es decir, sin sentido) a su disposición. No habría estructura habitable para su deseo. Claramente, entonces, el problema no afecta sólo a la lectura: la escritura se encontrará, también, con el problema de escribir al deseo imposible. Cortázar lo explicita en el prólogo que le escribe a la segunda versión de su cuento: "Lo que sigue es una tentativa de mostrarme a mi mismo que el texto de "La Barca" está mal escrito porque es falso, porque pasa al lado de una verdad que entonces no fui capaz de aprehender [...]" (2000, 135). Verdad que vuelve a ser silenciada por el autor al nunca hacerse explícita más que por elisión.

Por falta de una narrativa que sostenga su deseo, la lesbiana deberá utilizar discursos que no le pertenecen (como el amoroso). Como la ninfa del mito, hace eco a las palabras de sus interlocutores pero no puede por sí misma iniciar un discurso, dibujando así -en palabras de Dólar (2007)- la historia del fracaso de un amor y de un narcisismo. Sin embargo, a pesar de que los códigos textuales son aceptados, al haber un desplazamientoque aunque silencioso nunca es mudo-del contrato heterosexual se produce, inevitablemente, un desplazamiento epistemológico que cambiará los resultados en tanto posibilidad de acción, de significación, de conocimiento y de construcción de un lenguaje del deseo. En la adopción del código, entonces, el desvío sería el acto de resistencia.

En Fragmentos de un discurso amoroso, Roland Barthes (2008) explica que la persona fundamental del discurso amoroso es un Yo que habla en sí mismo frente a otro que no habla. En segundo lugar, sostiene que el discurso amoroso está fundado sobre los 
códigos de amor cortesano (y / o desdichado) y, por esto, se construye como discurso mitad expresivo (tópica amorosa), mitad vacío (que debe ser llenado con lo que más convenga). Ambas condiciones se cumplen en los textos analizados. Sin embargo, y a pesar de los esfuerzos de Eric Marty $(2006,169)$ por demostrar la subjetividad universal abstracta del sujeto enamorado barthesiano, Barthes parece pasar por alto el hecho de que el discurso amoroso es también un discurso sobre la sexualidad. Ésta, al ser construida en el campo de lo simbólico, está regulada por leyes (del lenguaje, sociales, etc.). Entonces, la pregunta obligada: el discurso amoroso ¿qué permite decir y a quién? ¿Qué proscribe y qué prescribe?

En “Carta perdida en un cajón”, lo vivido por la protagonista es claramente descrito en términos de lo que Barthes llamaría lo inactual o intratable del discurso amoroso, las figuras que "el enamorado extrae de la reserva [...] según las necesidades, las exhortaciones o los placeres de su imaginario" $(2008,20)$ :

\begin{abstract}
"Pensar de la mañana a la noche en tus ojos, en tu pelo, en tu boca, en tu voz, en esa manera de caminar que tienes, me incapacita para cualquier trabajo. A veces, al oír pronunciar tu nombre mi corazón deja de latir" $(2007 A, 243)$ y continúa: "Aquel día, en casa de nuestros amigos, al verte, una trémula nube envolvió mi nuca, mi cuerpo se cubrió de escalofríos. [...] sentí vértigo, nauseas [...]" (2007A, 245). Sin embargo, la insuficiencia del discurso amoroso para aprehender la experiencia lesbiana condenará a la protagonista a su propia ininteligibilidad: “¿Dónde está el experto? Necesito dar una explicación a mis actos" (2007A, 245), exclama.
\end{abstract}

Por otro lado, en "El piano incendiado", la falta de herramientas discursivas para expresar al amor lesbiano va a tener como consecuencia su traducción en una metáfora musical que sólo reafirmará su imposibilidad. El punto climático del cuento se produce cuando: "Herminia [...] en vez de mirar el piano, miraba a un joven a los ojos como si fuera la música. Entonces, sin saber lo que hacía, me acerqué y le dije: si sigues tocando el piano, lo incendio". Después de esto, la protagonista explica: “[...] nunca sabré cual era (esa música) [...] yo sigo con mi música dentro de mi oído, sin poder saber si era esa o si cantando desafino tanto que la gente no la reconoce [...]" (2007E, 321, las cursivas me 
pertenecen). La figura amorosa resuena fuera de los sintagmas posibles, en una nueva melodía que no puede ser identificada ni leída.

Haciendo explícito, de algún modo, lo establecido en párrafos anteriores, Dora, la protagonista de "La barca" de Cortázar, criticará como cliché los diálogos amorosos entre Adriano y Valentina al tildarlos de "diálogos de best seller" (2000, 145). Sin embargo, es ese mismo gesto el que denuncia a la cultura heterosexual como artificio al tiempo que pone en evidencia la carencia de recursos de las protagonistas para expresar lo que sienten.

A partir de esto, podría entenderse la razón por la cual, en los textos propuestos, junto con la aplicación del cliché, ingresa, invariablemente, el desvío: el amor de las protagonistas travestido en cólera y odio. Es el rodeo que la abyección exige: la injuria en lugar del beso. Explica la protagonista de "El piano incendiado": "Así fue como llegamos a una situación despareja, en que reinaba sobre mi, porque, debo confesarlo, yo la odiaba. Poco a poco advertí que la odiaba" $(2007,320)$.

Tal vez podríamos pensar, entonces, que el hecho de que haya que imaginar a la sexualidad en su máxima violencia para lograr la manifestación de la lesbiana revela la violencia con la que ha sido reprimida (Molloy, 1999). La ira y el odio re-significados. La pasión colérica erigida como forma posible de vivir el deseo y la pasión por otra mujer. Dice Dora en "La Barca": "Valentina, Valentina, Valentina, la delicia de que me lo reprocharas, de que me insultaras, de que estuvieras aquí injuriándome, de que fueras tu gritándome, el consuelo de volver a verte, Valentina, de sentir tus bofetadas, tu saliva en mi cara" (2000, 169); "A veces, ante cualquiera que la escuchara despotricar contra mí, parecía una enamorada. Para aguzar mi deseo de venganza, ella no desdeñaba ninguna traición" (Ocampo, 2000, 438), explica la narradora de "El lazo" y remata la protagonista de "El piano..." de Silvina Ocampo: "Hay algo en el dolor tan idéntico al más gran goce" $(2007,321)$.

Pero, por si quedó alguna duda, en "El diario de Porfiria Bernal" (1961) de Silvina Ocampo -donde se narra otra relación desigual entre mujeres aunque, por lo menos en una primera instancia, no en clave lesbiana-, se nos provee de una guía de lectura: "[...] cuando una no consigue el afecto que reclama, el odio es un alivio. El odio es lo único que puede reemplazar al amor" (2007, 
477). Reformulado: para quien siente un amor imposible (recordemos que el objeto está clausurado desde el comienzo), el odio y la cólera son la única opción. La herida amorosa, condición de existencia de este amor.

Será así que la pasión colérica, a pesar de que amenaza con la pérdida de control (como vemos, por ejemplo, en "El Lazo" y en "Memorias secretas de una muñeca"), se construye como el nicho en donde se mantiene vivo el sentido subjetivo de la identidad de las protagonistas; donde tienen la primera percepción, incierta, de $\mathbf{s i}^{7}$; donde se sostiene la marca de una subjetividad diferente a la del resto.

En "Carta perdida..." Ocampo escribe: "En el fondo de mi corazón se retorcía una serpiente semejante a la que hizo que Adán y Eva fueran expulsados del paraíso" (2007, 244). Si bien, en la topografía del cuerpo, el corazón suele ser el lugar donde se representa al amor, en los cuentos es este un amor impuro que fascina y repugna, que atrae a las protagonistas hacia el lugar donde el sentido $\mathrm{cae}^{8}$; que exige quebrar la Ley y que, por eso, implica la expulsión y la culpabilidad (en el caso de "El Lazo", el asesinato llevará esto al extremo).

Pero cuando la trasgresión del tabú (del lesbianismo) intenta volverse palabra, tenderá a desarrollar, en los cuentos analizados, un discurso en torno a la culpa y, consecuentemente, lo que ésta supone: la confesión/declaración (forma también imprescindible para el amor). Conjunción de un pedido de amor y un pedido de juicio, en boca de alguien (en este caso una mujer) que se posiciona como sujeto de acción y de deseo: "Acto en el que una subjetividad se fortalece afirmándose en falta" (Podlubne, 2004, 22).

Porque, además, lo que resulta interesante es que es sólo este acto lo que importa en los cuentos. Si el mensaje llega a destino queda en un segundo plano. La voz se mantiene en un lugar central, no la escucha, y el deseo del relato sería el propio (el de las protagonistas), no el de la interpelación.

Estos relatos retrospectivos narran la pérdida de un origen pero, además, en ellos, la frase de Lacan: "amar es necesidad de ser amado por aquel que podría tomarlo a uno como culpable" (Cit. en Gerez Ambertín, 2000, 3) estalla en posibilidades que, como vimos, necesariamente y a priori, sostienen al amor o al perdón como imposibles. Es por esto que el duelo se presenta como 
la figura constante; la pérdida, lo presente desde el comienzo. Y al sujeto dolido (y doliente) son los celos, la pasión que lo acompaña.

Como se sabe, el duelo se produce frente a la pérdida del objeto amado. Según Freud (1981A), la consecuente exhortación a deslibidinizar todo lo relativo a éste generalmente se acataría con renuencia (produciendo momentáneos extrañamientos de la realidad) e implicaría un proceso doloroso y progresivo. En el caso de nuestras protagonistas, dado que el objeto aparece clausurado desde el comienzo, el displacer doliente se presenta como la condición amatoria y el retorno al origen (posibilidad del relato), la expresión de su deseo.

En todos los cuentos, el conflicto pasional llega a su punto de máxima violencia en el momento en que un triángulo amoroso se convierte en díada, cuando la protagonista es "una vez más la outsider" (Cortázar, 2000, 161). Los celos, entonces, aparecen como pasión de la que se oculta (celda y celos tienen el mismo origen etimológico), de quien en celo es devorada por el ardor hacia el objeto que desea pero que le produce sufrimiento al preferir a otro.

Como era de suponer, el problema de la (in)viabilidad, o incluso, de la (in)visibilidad de la pasión lesbiana no se presenta solamente en el nivel de la enunciación o de la lectura. Confirmando, por lo menos en una primera instancia, la teoría de Judith Butler (2000) de que la lesbiana no habría sido construida socialmente como objeto prohibido sino como sujeto inviable -ni nombrado ni producido dentro de la economía de la ley-, las protagonistas de los cuentos surgen en la tensión entre la materialidad de la palabra y la ausencia de cuerpo y rostro.

Sin embargo, es posible pensar, y ahora sí acercándonos a la paradoja propuesta por Jagose $(2002,2)$-citada en la introducción-, que esa inviabilidad es la condición de existencia de las protagonistas. Es decir, que tanto para Córtazar como para Ocampo funcionaría como posibilidad y fundamento (en su doble sentido) de una productiva estrategia de representación. Es la puesta en escena de lo que no existe, el movimiento simbólico que, por un lado, denuncia que lo no (re)presentable (lo inimaginable, lo innombrable, lo invisible) no es sino producto de un recorte de la mirada y que, por otro lado, da lugar a la paradoja que permite leer en la falta la presencia.

El cuerpo de la voz lesbiana será construido, acorde con lo 
desarrollado, como campo de tensión entre invisibilidad y visibilidad, entre imposibilidad y posibilidad, entre resistencia y aceptación. Mientras que la protagonista de "El piano incendiado" comienza diciendo: "Miré mi cara [...]. Ahora se nota el paso del tiempo, que arrugó los contornos de los párpados y dejó el resto casi borrado" (2007, 319), la de "El lazo" sostiene "Yo me desfiguraba" (2007, 437-8) y la de "Memorias secretas..." termina afirmando: "la vida sigue ya sin cuerpo [...]" $(2007,249)$. Dora, la protagonista del cuento de Cortázar, es desde el principio construida como una pura voz que interrumpe, constantemente, el relato central en tercera persona, reclamando presencia: "Claro que yo estaba", comienza diciendo, "Desde el comienzo se finge no verme, reducirme a comparsa ..." $(2000,137)$, y más tarde: “Yo soy deliberadamente deformada y ofendida [...]" $(2000,160)$.

En "Año cero-Rostridad", Deleuze y Guattari (1997) proponen que ciertos agenciamientos de poder tienen necesidad de producir rostros (junto con la cara se rostrificaría el resto del cuerpo) y, por ende, de prescribir otros, rechazando a aquellos inadecuados y neutralizando "[...] las expresiones y conexiones rebeldes a las significaciones dominantes" $(1997,174)$. De este modo, el rostro no constituiría en sí mismo un dispositivo de individualidad sino una tecnología política: el rostro como el verdadero porta-voz.

Si seguimos esta línea de pensamiento, podría positivizarse la falta de corporeidad de las protagonistas de los cuentos de Cortázar y Ocampo en términos de resistencia. La carencia de rostro pondría en vilo a los lugares sociales que él sostiene, al tiempo que re-ubicaría, en su independencia, a la voz. De este modo, el rostro deshecho, la línea de fuga tendida.

Sin embargo, la "celda" y la "prisión" no desaparecen. "Vivo como en una celda donde nadie puede entrar" $(2007,247)$, dice la protagonista de "Memorias secretas..." y la de "Carta perdida..." escribe al final de su carta: "Entonces te internarás en un jardín semejante al del colegio que era nuestra prisión" (2007, 246). Es así que los "destinos" propuestos por Deleuze y Guattari de devenir-imperceptible y devenir-clandestino son negativizados por los cuentos en tanto son reformulados en términos de mantener(se) imperceptible y clandestino. Entonces, la línea de fuga resignificada en huida (presente en su relación con la muerte) es medio para enmascarar el duelo. 
A partir de la lectura propuesta, puede verse el modo en que, si practicamos una lectura desviada sobre los textos hegemónicos -en este caso, una selección de cuentos de Silvina Ocampo y de Julio Cortázar- se devela un más allá que nunca es explícito, que estalla de legibilidad por lo mismo que calla. Al problematizarse los modos de narrar (y de leer) lo proscripto y lo implícito, se hace visible una sutil confrontación con los códigos sexuales y textuales que denuncia, en forma torcida, a un orden social que, obturando, establece relaciones sociales jerárquicas y de poder (entre los sexos, en relación a las diferentes elecciones de objeto amoroso, etc.).

La emergencia de la voz lesbiana puede leerse, entonces, como la emergencia provocada por lo que oculto se vuelve, de pronto, abrumador: la voz lesbiana situada "[...] en ese punto no localizable en el interior y en el exterior de la ley al mismo tiempo [...]" (Dólar, 2007, 145). Es por este mismo juego entre adentro y afuera que más que una construcción sobre el deseo eróticoamoroso lesbiano, los cuentos construirán un discurso acerca de la imposibilidad de reconocer, hablar y actuar tal deseo. El discurso amoroso, en palabras de las protagonistas, un discurso de "pánica soledad", de "soledad inextinguible".

"Se hereda siempre un secreto-que dice: "Léeme. ¿Serás capaz de ello?"”

Jacques Derrida

Volvamos por un instante al prólogo de Cortázar ya citado: "[...] "La Barca" está mal escrito porque es falso, porque pasa al lado de una verdad que entonces no fui capaz de aprehender [...]" (2000, 135). Años después, en la primera década de un nuevo siglo, ese mea culpa individual es generalizado por Sylvia Molloy (2005) en su título: El común olvido. Reformulado: el frecuente olvido o el olvido de todos -privativo de nadie-. El descuido de algo que se debía tener presente. Es decir, en el presente.

Pero además, podría, tal vez, asociarse el título de Molloy a la celebre idea de Freud (1981B) de que la cultura sería el 
producto de un crimen cometido en común. Como explica Eduardo Gruner en El sitio de la mirada: "[...] que en el propio origen mítico haya un acto catastrófico que es la causa misma del Deseo, causa perdida desde siempre pero eficaz en sus retornos insistentes, es lo que hace de la obra de cultura un síntoma, y lo que la instituye no como conteniendo sino como siendo un malestar [...]" (2001, 28). El acto catastrófico, esta vez, reformulado en olvido.

A partir de esto, propongo que esta novela, escrita en un contexto social en el que la diversidad sexual ya está en la agenda política-cultural internacional, pone en escena y problematiza, sin inocencia, todo aquello desarrollado en el primer apartado y sin embargo, no hace sino, de algún modo, replicarlo (probablemente, en sus dos sentidos). A pesar de los años (de vida y de literatura) el lesbianismo seguirá siendo, en El común olvido, la gran omisión. Ese olvido originario (que, como el pecado, será castigado con el exilio), al igual que en los cuentos de Cortázar y Ocampo, se construye como vórtice donde la palabra cae pero que, paradójicamente, estructura al relato.

Sylvia Molloy publicó en el año 1981 En breve cárcel, una novela que ha jugado un papel inaugural en lo que algunos llaman literatura lesbiana (argentina) y en la que, que a partir del relato de un triángulo amoroso, se construirá al lesbianismo como (razón de) reflexión sobre el acto de escritura. En el año 2003, Molloy publicará Varia imaginación, un pequeño libro de tinte autobiográfico, integrado por historias breves que dibujan imágenes del pasado. "Curiosamente", aquella que da título al libro será el relato del coming out de la narradora ante su madre.

Sin embargo, El común olvido exige otro orden, tiene otras prioridades. El primer plano está puesto en lo que se olvida y en lo que se calla. Publicada en el año 2002, esta novela se mueve, temporalmente, entre los años treinta, sesenta y la actualidad, dibujando un paisaje tanto geográfico como intelectual. El narradorprotagonista es Daniel, un joven homosexual que vive en Estados Unidos y que, tras la muerte de su madre (Julia), decide volver a Buenos Aires. Allí se verá enfrentado a sus recuerdos (y a los recuerdos de aquellas personas que conocían a Julia) pero, sobre todo, a sus olvidos, especialmente los relacionados con su madre.

Hay un misterio (o secreto) central que ronda a la madre de Daniel que recién será develado en la segunda parte de El común 
olvido, por la voz de Charlotte Haas. Voz que es vivida por Daniel como amenaza de agresión inminente $(2005,231)$ y es descripta como "ronca y aflautada a la vez, [...], desagradable" $(2005,228)$, una "voz baja, monótona, urgente, que no toleraba interrupciones" (2005, 333-34) y que "no permite saber del todo si (quien habla) es hombre o mujer" (2005, 228).

Esa voz "andrógina" es la voz lesbiana que toma la palabra en el siglo XXI para decir (o para denunciar) lo que en las décadas previas habría permanecido silenciado en forma simbólica y real. Es la voz que pone en escena el hecho de que la memoria es constitutivamente una falta (en sus dos acepciones) y que es sobre esa falta que se organiza la historia.

La voz lesbiana de El común olvido ya puede decir su amor (y, como en una suerte de genealogía, el de las anteriores que no pudieron decirlo) y es, esta vez, el hombre (hijo o esposo), el sujeto doliente que queda excluido, el que no soporta escucharla. Como consecuencia, si bien la prohibición no existirá a priori, aparecerá en el momento en que lo invisible se haga visible. La violencia no resulta ya producto de la represión sino que es la forma que adquiere la represión misma. Se mueven los engranajes de la mecánica ejemplar del castigo: "Y entonces cuenta, con la misma voz monocorde [...], cómo mi padre se vengó de ellas [...]; cómo, decía Charlotte que le decía mi madre lo había vivido como una intolerable pérdida de control que parecía poner en tela de juicio su identidad misma" (Molloy, 2005, 344, las cursivas me pertenecen).

Porque si, como sostuve con anterioridad, es en el apogeo de la pasión lesbiana donde se construye la subjetividad de las protagonistas, es, ahora, en ese mismo instante donde el sujeto masculino es desposeído y su subjetividad vacila: "[...] tu padre encontró a un tipo que le hizo el favor de alejarme de tu madre para siempre [...]. Me insultó y me pegó [...], como si él fuera el ultrajado [...], me pegó hasta que me quebró la mandíbula [...] y perdí el conocimiento. [...] Casi perdí un ojo. No fui a la policía, no hice nada: era extranjera, era judía, no quería líos" (Molloy, 2005, 344, las cursivas me pertenecen).

Pero lo más importante: era lesbiana. Paradójicamente, la voz lesbiana se encuentra con un nuevo problema: puede decir su amor (y utilizar las palabras que entran en su campo semántico: enamorada, amante, hacer el amor) pero no puede identificarse. Nuevamente, no consigue escapar a su propia negación. 
Lo propio de la voz lesbiana deviene así no-apropiación, presencia ausente, y queda sujeta, nuevamente, a lo que no es texto, a lo que lo excede.

Si bien alguien puede leer en esto un acto de resistencia o incluso pensar que El común olvido pone en escena las incoherencias de las definiciones de la sexualidad y de los códigos culturales, no puede ignorarse que, más allá de las contradicciones que efectivamente construye, hay una serie de palabras que se repiten estableciendo identidades (a modo de ejemplo, cito algunas relacionadas con el tema de este trabajo: heterosexual, homosexual, puto, maricón, gay). La indefinición de la voz lesbiana como lesbiana, es decir, la omisión, más que hacer caer a los binarismos y sus efectos ideológicos, testimonia su existencia al tiempo que confirma la normatividad de lo masculino.

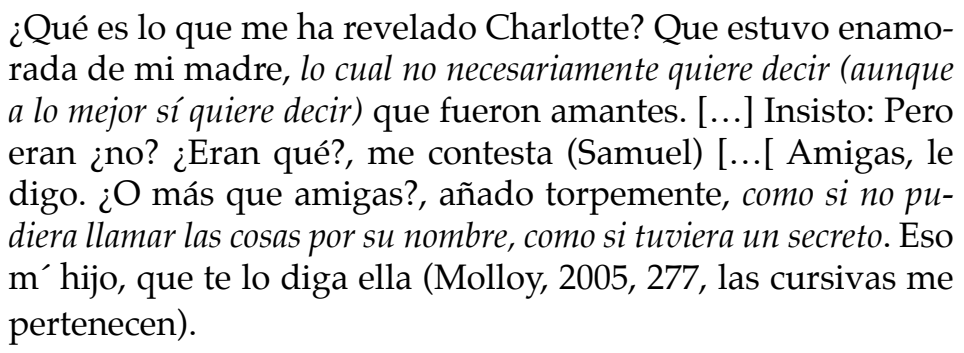

Pero "eso" nunca es dicho por "ella" ni por ninguno de los otros personajes (la obviedad reemplaza a la palabra). El sustantivo se mantiene en secreto, agazapado tras su propia expresión performativa. Como si... ya no es algo que se deba confesar o declarar, se encuentra abierto a la mirada pero no se nombra: tal vez porque sigue siendo lo que todavía no tiene porvenir, tal vez porque, como señala Jacques Derrida (2009) con respecto a la literatura: "Allí estaría la pasión. No hay pasión sin secreto, este secreto, pero no hay secreto sin esta pasión".

Es así que la voz lesbiana se construirá como la voz del secreto. Pero si en los cuentos de Ocampo y Cortázar era este un secreto cifrado, que no encontraba palabras propias y que obligaba a la voz a asumir cuerpo sobre su propia imposibilidad, ahora la voz lesbiana se asume como secreto a voces: comprende las reglas que se le imponen y las interpreta. La pose residirá en guardar las apariencias.

Leemos en una entrada del diario de Julia, madre de Daniel: 
“Entre las cosas que me echó en cara, Charlie me preguntó si alguna vez había hecho el amor con una mujer. Le dije que no pero que las ganas no me habían faltado, para hacerlo rabiar. What does he know" (Molloy, 2005, 307). Y la pregunta se repite: y nosotros, como lectores ¿Qué es lo que sabemos?

Más adelante dice Daniel con respecto a un relato de Charlotte: "Quise interrumpir este monólogo que me ponía sumamente incómodo, que casi me chocaba. La sexualidad de mi madre pertenecía, o había pertenecido hasta entonces, a lo que no tiene nombre, y ahora los detalles que me daba Charlotte me empujaban a nombrarla" (Molloy, 2005, 334, las cursivas me pertenecen). Sin embargo, como era de esperar, empujón no es caída: la sexualidad de Julia va a continuar sin ser nombrada.

Poseer este secreto no sólo significa que también (y sobre todo) lo posean las personas del entorno (y, por supuesto, el lector), sino que, en algún punto, depende de la mirada interpretativa (o mejor dicho, de la ceguera interpretativa) de quien funciona como autoridad del relato.

Hacia el final de la novela, Daniel explica, refiriéndose a Beatriz (sobrina de su madre): “Quiero preguntarle cuándo y dónde conoció a Charlotte, [...] si son amantes, y si sí, desde cuándo, y si lo sabía mi madre, y si mi madre y Beatriz. Sé que contestaría con evasivas pero, sobre todo, sé que no soportaría enterarme de una cosa más" (Molloy, 2005, 322, las cursivas me pertenecen).

Pero esta última afirmación se delata falsa en la línea siguiente, porque las preguntas a Beatriz continúan. Lo que Daniel no soportaría es la confirmación explícita, el definir a la madre con el lenguaje del deseo (de la otra). Lo que espera -o lo que puede soportar- (el oyente, el lector) de la voz no es un nombre ni una identidad, sino la elisión constante. Acorde con el deseo del narrador, el lesbianismo vuelve a construirse como efecto de la sospecha, permitiendo "[...] homosexual meaning to be elided even as it is also being elaborated" (Jagose, 2002, 27).

Así, Charlotte narrará y Julia escribirá en su diario, a partir del relato del pasado, escenas de su vida pero no su existencia. Su deseo sin nombre -que, como en los cuentos anteriores, es prisión y liberación-, se construye en el juego entre lo que se nombra y lo que no se nombra (o entre lo que se lee y lo que no se lee) y se erige como dispositivo sobre el que se sostiene tanto la lectura como la escritura. Es decir, el relato. 
Volvamos al principio. Ese primer encuentro en la confitería París entre Daniel y Charlotte comienza con este diálogo: "Posiblemente no se acuerde de mí. Asiento, inseguro. Me parece que no, le contesto.... Mejor así, me contesta, complacida..., de este modo el placer del cuento es mío" (Molloy, 2005, 232, las cursivas me pertenecen).

La voz lesbiana asume el relato en primera persona: "yo cuento". Pero, si se busca en el diccionario, "cuento" es también un relato indiscreto o uno de pura invención. La voz lesbiana dibujará así al pasado (y, por ende al presente) en los límites de la ficción. El cuento no sólo resultará habilitado para contar lo que nunca se ha contado -los chismes de la historia, lo prohibido-, sino que, como ficción, se erigirá en el espacio liminal entre la verdad (porque no puede evitar contarlo todo) y lo que nunca existió.

Pero además, si nos dejamos tentar por la cercanía entre la frase de Charlotte y el título de Barthes, El placer del texto (la diferencia no hace sino acercarlos), podemos tomar a este último como clave de lectura: "[...] todo texto sobre el placer será dilatorio: una introducción a aquello que no se escribirá jamás" (Barthes, 2000, 31). Corrijo: a aquello que no se dirá jamás (y agrego: por lo menos en el libro).

Lo que resulta interesante, sin embargo, es que, al igual que en los textos analizados en el segundo apartado y reproduciendo el conflicto allí planteado, el problema de la representación de la lesbiana no se presenta solamente en el nivel de la enunciación. Las protagonistas también surgirán en $E l$ común olvido en la tensión entre la materialidad de la palabra y la ausencia de cuerpos y rostros: Beatriz no recuerda a Julia porque ve borrosas las caras del pasado (Molloy, 2005, 56), Charlotte ve borrosa la cara de la gente y luce anteojos oscuros que enmascaran sus propias facciones (Molloy, 2005, 233); Julia deja un diario, pero de su cuerpo sólo quedan cenizas en una urna que desaparecerá. Daniel busca constantemente la imagen de su madre bajo la pregunta ¿era linda? y nunca recibe la respuesta que le permita esbozar el rostro previo al de su muerte, pero cuando le llega a él el turno de describir a Beatriz sólo puede decir: "no podría describirla con fidelidad porque no sé describir bien a las mujeres. Sólo sabría decir que tenía la belleza terrible y dorada de un león" (Molloy, 2005, 26). 
Claramente, a lo largo de la novela (y al igual que en los cuentos anteriores) son dos los sentidos que están en pugna: la vista y el habla. Sin embargo, la afirmación más fuerte con respecto a este conflicto ( $\mathrm{y}$ con esto quiero decir que como un ritornello volverá rítmicamente, (des)dibujando rostros) son dos cuadritos gemelos pintados por Julia que remitirán al(a) lector(a), sin demasiado esfuerzo, a ese cuadro de Vermeer que Daniel llama el cuadro del secreto y frente al que se preguntará: “¿Cuál era esa otra escena, para siempre vedada al espectador, placentera o terrible, o las dos cosas a la vez [...]?" (Molloy, 2005, 271). La voz lesbiana, ahora inscripta en óleo, para siempre (jamás) dando testimonio de que esa otra escena continuará vedada, apenas insinuada:

En el ángulo inferior izquierdo se veía un niño, de espaldas, espiando por una puerta entreabierta. El niño tiene pelo rojizo como yo, está desnudo, y de su hombro derecho parece salir algo, como un muñón de ala; espía el interior de un cuarto con una cama a medio hacer, infinitamente repetida en las hondísimas perspectivas de las tres fases del espejo, reflejada desde un afuera del marco, la cara borrosa de una mujer. (Molloy, 2005, 320 , las cursivas me pertenecen).

El cuadro obliga a la mirada a centrarse en un punto ciego en el que brilla la ausencia. Pequeño rectángulo reluciente que testimonia una acción en el pasado. Pero el espejo restituye lo que escapa a la vista y por cercanía, el espectador pone en relación la cama, el rostro (inidentificable) de una mujer y, dato que hasta ahora negué al(a) lector(a), la pregunta escrita en el revés del cuadro: “¿Te gustaba mirarnos?” (Molloy, 2005, 331). Esa interpelación al "tú" (finalmente llamado a escena) denuncia que lo "invisible" habría siempre visto, que lo "innombrable" o "inviable" no sería sino una elección de la mirada.

Pero además, con una simple pregunta -“ ¿Te gustaba mirarnos?"-, la voz lesbiana pasará, como el reflejo en el espejo, de una primera persona singular a sostener su plural. Un plural que en el "nosotras" compartido, en las últimas páginas, por Charlotte y Beatriz, promete escapar al pasado para convertirse en presente. 


\section{Notas}

1 Instituto Interdisciplinario de Estudios de Género, UBA/CONICET. laura_arnes@hotmail.com

2 Para un análisis más profundo sobre este tema, ver: Dólar, Mladen. Una voz y nada más, Buenos Aires: Ed. Manantial, 2007.

3 Judith Butler, complejizando un poco más la narrativa edípica, establece en El género en disputa que:

El tabú contra el incesto, y de manera implícita contra la homosexualidad, es un precepto represivo que implica un deseo original situado en la noción de "disposiciones", el cual padece la represión de una inclinación libidinal originalmente homosexual y genera el fenómeno desplazado del deseo heterosexual. La estructura de esta metanarración concreta del desarrollo infantil entiende las disposiciones sexuales como los impulsos prediscursivos, temporalmente primarios y ontológicamente separados que tienen un objetivo y, por consiguiente, un significado previo a su aparición en el lenguaje y la cultura. Su misma entrada en el campo cultural aleja ese deseo de su significado original, y como consecuencia el deseo dentro de la cultura es obligatoriamente un conjunto de desplazamientos. Así, la ley represora engendra la heterosexualidad, y actúa no sólo como un código negativo o excluyente, sino como un castigo y, de forma más apropiada, como una ley del discurso, que diferencia lo decible de lo indecible (estableciendo y elaborando el campo de lo indecible), lo legítimo de lo ilegítimo $(2007,150)$.

y continúa:

Activar la distinción entre lo que es "antes" y lo que es "durante" la cultura es una manera de excluir opciones culturales desde el principio. El "orden de aparición", la temporalidad que es la base del análisis, así como refuta la coherencia narrativa al introducir la separación en el sujeto y la félure en el deseo, también reinstaura cierta coherencia en el nivel de la exposición temporal. El resultado es que esta estrategia narrativa, que trata sobre la distinción entre un origen irrecuperable y un presente permanentemente desplazado, provoca que sea inevitablemente tardío todo intento por recuperar ese origen en nombre de la subversión $(2007,171)$.

4 Según explica Jagose $(2002,81)$ leyendo a Freud, los homosexuales mantendrían una relación conflictiva con la memoria al mismo tiempo que la homosexualidad se configuraría como memoria.

Pero además, el psicoanálisis habría tendido a pensar a la homosexualidad femenina en términos de anterioridad (pre-edípica, pre-simbólica, pre-vaginal...). Ver, a modo de ejemplo: Freud, Sigmund. "Sobre la sexualidad femenina", Obras Completas, Tomo III, Madrid: Biblioteca Nueva, 1981, 3077-3089.

5 Se puede citar, a modo de ejemplo, Le fantastique argentin, Silvina Ocampo, Julio Cortázar, América, 17 (1997). 
6 Para poder hacer esta afirmación, me baso en la definición de voz lesbiana desarrollada en párrafos anteriores. Si bien durante el período propuesto pueden rastrearse otros cuentos de "temática lésbica", incluso escritos en primera persona, considero que en este conjunto propuesto son otros los problemas que en ellos se construyen. Al mismo tiempo pienso el concepto de voz lesbiana como un problema a seguir explorando en otros autores / as de la literatura argentina. En este sentido, advierto una manera particular de tratamiento de esta cuestión que me permiten hablar de emergencia.

7 Para más información sobre la historia epistemológica de la "pasión" y la "cólera", ver: Bordelois, Ivonne. Etimología de las pasiones. Buenos Aires: Zorzal, 2006.

8 Esto coincide con la definición que Julia Kristeva propone para el término abyecto: aquella realidad perturbadora de un orden que "si la reconozco, me aniquila". Poderes de la perversión. México: Siglo XXI, 1989, 11.

\section{Bibliografía}

Barthes, Roland. El placer del texto. México: Siglo XXI, 2000.

-----. Fragmentos de un discurso amoroso. Buenos Aires: Siglo XXI, 2008.

Butler, Judith. "Imitación e insubordinación de género". Grafias de Eros. Buenos Aires: Edelp, 2000, 87-114.

-----. El género en disputa. Barcelona: Paidos, 2007.

Cortázar, Julio. "La barca". 1976. Historias de un deseo. Ed. Leopoldo Brizuela. Buenos Aires: Planeta, 2000, 135-169.

Costantini, Gustavo. "Poderes del acúsmetro. En torno a la voz y la acusmática. Lacan, Chion y Zizek". Psikeba. 2009. http: / / www.psikeba.com.ar/articulos/GCacusmetro.htm

Deleuze, Gilles y Felix Guattari. "Año cero-Rostridad". Mil mesetas. Valencia: Pre-textos, 1997, 173-196.

Derrida, Jacques. "Pasiones: La ofrenda oblicua”. Derrida en castellano. 2009. http: / / www.jacquesderrida.com.ar/textos/pasiones.htm

Dólar, Mladen. Una voz y nada más. Buenos Aires: Ed. Manantial, 2007.

Freud, Sigmund. "Duelo y melancolía". Obras Completas. Tomo III, Madrid: Biblioteca Nueva, 1981A, 2091-2100.

-----. "Tótem y Tabú". Obras completas. Tomo III, Madrid: Biblioteca Nueva, $1981 B, 1745-1850$.

Geréz Ambertín, Marta. "Seducción de lo prohibido (Clandestinidades del amor)". Debate Feminista. 25/13 (2002): 309-318.

Gruner, Eduardo. El sitio de la mirada. Buenos Aires: Norma, 2001.

Jagose, Annamarie. Inconsequence: Lesbian Representation ande the Logic of Sexual Sequence, New York: Cornell University Press, 2002.

Kosofsky Sedwick, Eve. "Epistemología del closet". Grafias de Eros. Buenos Aires: Edelp, 2000, 53-86.

Mancini, Adriana. Silvina Ocampo, Escalas de pasión. Buenos Aires: Vitral, 2003.

Marty, Eric. Roland Barthes, el oficio de escribir. Buenos Aires: Manantial, 2006.

Molloy, Sylvia. "De Saffo a Baffo: Diversiones de lo sexual en Alejandra Pizarnik". Estudios. 13 (1999): 133-140.

-----. El común olvido. 2002. Buenos Aires: Norma, 2005. 
Ocampo, Silvina. “Carta perdida en un cajón”. 1959. Cuentos completos I. Buenos Aires: Emece, 2007A, 243-246.

-----. "El lazo". 1961. Cuentos completos I. Buenos Aires: Emece, 2007B, 440-443.

-----. "El diario de Porfirio Bernal". 1961. Cuentos completos I. Buenos Aires: Emece, 2007C, 460-479.

-----. "Memorias secretas de una muñeca". 1987. Cuentos completos II. Tomo. Buenos Aires: Emece, 2007D, 247-250.

-----. "El piano incendiado". 1988. Cuentos completos II. Buenos Aires: Emece, 2007E, 319-321.

Villarejo, Amy. Lesbian Rule, cultural criticism and the value of desire. New York: Duke University Press, 2003. 